\title{
Article
}

\section{The Wear Resistance of Cryogenically Treated Diamond-Like Carbon Films}

\section{Lee-Long Han ${ }^{1}$, Chun-Ming Lin ${ }^{1, *}$ and Yih-Shiun Shih ${ }^{2}$}

${ }^{1}$ Graduate Institute of Mechanical and Electrical Engineering, National Taipei University of Technology, Taipei 10608, Taiwan; 1lhan@ntut.edu.tw

${ }^{2}$ Department of Mechanical Engineering, National Taipei University of Technology, Taipei 10608, Taiwan; ys8034@yahoo.com.tw

*Correspondence: 1cd@mail.tyai.tyc.edu.tw

\begin{abstract}
This study explored the effects of cryogenic treatment on the microstructure, hardness, and wear-resistance of diamond-like carbon (DLC) by cryogenically treating NAK 80 mold steel coated with DLC. Raman spectroscopy analyzed the structure of the DLC film. Nanoindenter analyzed the hardness and Young's modulus of the film, and their relationship determined the wear resistance. Wear test assessed the wear rate and friction coefficient of the DLC film. The results showed that cryogenic treatment increased the rate of carbide precipitation and refined the grain structure. Raman spectroscopy indicated that the Raman intensity rate $\left(\mathrm{I}_{\mathrm{D}} / \mathrm{I}_{\mathrm{G}}\right)$ of treated DLC films was smaller than those without cryogenic treatment. When the sp3 bond increased, the hardness and wearresistance of the DLC film also increased.
\end{abstract}

Keywords: Cryogenic treatment; wear resistance; Raman intensity rate

\section{Introduction}

Cold treatments primarily involve subzero treatment and cryogenic treatment. Ultra cryogenic treatment performed in this study is also known as ultra-cold treatment and refers to a method of processing materials at temperatures below $-196{ }^{\circ} \mathrm{C}$ and is an extension of cryogenic treatment. Cryogenic treatment not only substantially improves the mechanical properties and lifetime of ferrous metals, non-ferrous alloys, carbides, plastics (including nylon and Teflon), silicates, and other materials, but also stabilizes material size, improves uniformity, reduces deformation, exerts no damage on work pieces, generates no pollution, and has considerable economic benefits and market prospects. The principle involves using both liquid oxygen and liquid nitrogen as cooling materials to reduce the temperature below 0 ${ }^{\circ} \mathrm{C}$. The low temperature is used to improve the unstable and easily deformable characteristics of the metal material by rendering the composition delicate, the structure uniform, and producing precipitates that eliminate internal residual stresses. ${ }^{1-4}$

The structure of the diamond-like carbon (DLC) film is a mixture of $\mathrm{sp}^{2}$ graphite plane bonds and $\mathrm{sp}^{3}$ tetrahedron diamond covalent bonds. With a high proportion of $\mathrm{sp}^{2} / \mathrm{sp}^{3}$, its structure and properties are similar to that of a natural diamond. Specifically, the structure is similar to a diamond because it possesses the properties of high chemical stability, a low friction coefficient, excellent thermal conductivity, low adhesion, high wear resistance, and high hardness (HV 1500-5000). ${ }^{5}$

\section{Experiment}

\subsection{Experimental procedure}

In this experiment, NAK80 mold steel specimens were employed. The composition of these specimens is listed in Table 1. The experiment was divided into three stages. In the first stage, the cathodic arc plasma 
coating methodwas applied under a fixed target voltage, and a graphite target was used as the DLC film source. Its coating parameters are presented in Tables 2 and 3.

In the second stage, the hydrogen DLC film and the substrates underwent cryogenic treatment before slowly cooling to the temperature of liquid

Table 1 NAK80 compositional analysis

\begin{tabular}{|c|c|c|c|c|c|c|c|}
\hline Wt.\% & C & $\mathbf{S i}$ & $\begin{array}{c}\mathbf{M} \\
\mathbf{n}\end{array}$ & $\mathbf{N i}$ & $\begin{array}{l}\mathbf{C} \\
\mathbf{u}\end{array}$ & $\begin{array}{c}\mathbf{M} \\
\mathbf{0}\end{array}$ & Al \\
\hline $\begin{array}{c}\text { NAK8 } \\
0\end{array}$ & 0.15 & $\begin{array}{l}0 . \\
3\end{array}$ & 1.5 & $\begin{array}{l}3 . \\
0\end{array}$ & 1.0 & 0.3 & $\begin{array}{l}1 . \\
0\end{array}$ \\
\hline
\end{tabular}

Table 2 CAPD process parameters

\begin{tabular}{lc}
\hline & Process Process Process \\
\hline Doping & \multicolumn{2}{c}{$\mathrm{S}$} \\
\hline Target & $\mathrm{C}$ \\
\hline Reaction gas & $\mathrm{C}_{2} \mathrm{H}_{2}, \mathrm{H}_{2}$ \\
\hline Target current $(\mathrm{A})$ & 50 \\
\hline Coating temperature $\left({ }^{\circ} \mathrm{C}\right)$ & $270-300$ \\
\hline Chamber pressure $(\mathrm{Pa})$ & $0.33-0.35$ \\
\hline DC bias $(\mathrm{V})$ & -500 \\
\hline Deposition time (min) & 50 \\
\hline
\end{tabular}

Table 3 Gas response rate

\begin{tabular}{llll}
\hline specimen & $\mathrm{H}_{2}(\mathbf{s c c m})$ & $\mathbf{C}_{2} \mathrm{H}_{2}(\mathbf{s c c m})$ & $\begin{array}{l}\text { Doping } \mathbf{S i} \\
(\mathbf{s c c m})\end{array}$ \\
\hline Process 1 & 800 & 600 & 0 \\
Process 2 & 400 & 600 & 20 \\
Process 3 & 300 & 600 & 20 \\
\hline
\end{tabular}

nitrogen $\left(-300^{\circ} \mathrm{F}\right)$. After maintaining this temperature for an appropriate time, low-temperature tempering $\left(300^{\circ} \mathrm{F}\right)$ was conducted, and the furnace was cooled to room temperature. The substrate specimens were labeled S, and those subjected to coating were numbered 1, 2, and 3 . The specimens that were coated and underwent cryogenic treatment were labeled $\mathrm{C} 1$, $\mathrm{C} 2, \mathrm{C} 3$, and $\mathrm{CS}$. In the third stage, the coating structure, wear resistance, friction coefficient, wear rate, and hardness were separately explored.

\subsection{Cathode arc plasma deposition}

This study applied a coating method that uses cathode arc plasma deposition (CAPD), a part of the physical vapor deposition (PVD) system. The lowvoltage arc process of high-energy PVD generates enhanced bonding and a high-density coating. CAPD exhibits a high coating speed, favorable adhesiveness, and ideal coating quality, which facilitate prolonging the lifespan of the mold. Recently, CAPD has been frequently applied to material surface processing. ${ }^{6,7}$ CAPD involves an arc ignition caused by the instantaneous attachment and detachment of arc electrodes and cathode target surfaces, which enables a continual arc discharge between cathodes and anodes. The arc source is a low-voltage high-current power system that generates a high-energy arc to stimulate the atoms of target materials, thereby producing ionized plasma. The electric current is concentrated on cathode surfaces to form single or multiple cathode spots. In front of the cathode spots are high-density metallic plasma. Electrons move rapidly toward anodes, causing cations to accumulate in front of the cathode spots, forming a positive space charge. Intense electric field is produced near the cathode, enabling a continual arc discharge. Ion bombardment on the cathodes induces hightemperature evaporation and ionization at the cathode spots, which form metallic ions and become the source of droplet evaporation. Because the cathode spots are constantly moving, cathode materials continue to evaporate, generating metallic ions, which then react with reaction gases channeled through the materials to form compounds that are deposited on the surfaces of 
work pieces or substrates. Tables 2 and 3 list the parameters used in this study, and Fig. 1 shows a schematic diagram of the CAPD equipment. In this study, silicon was added to DLC film to enhance the film's wear resistance.

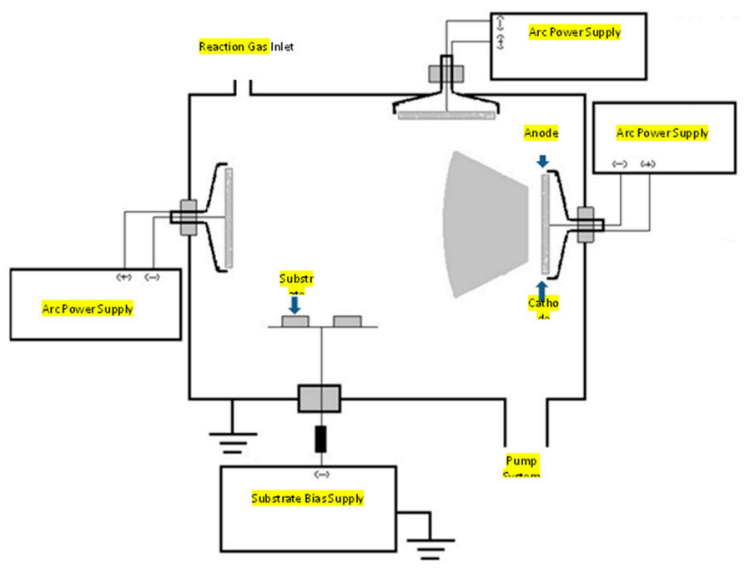

Fig. 1 Schematic diagram of the CAPD equipment

\subsection{Cryogenic treatment}

During the experiment, cryogenic treatment was performed to stabilize NAK80 mold steel. After quenching and tempering, the specimens were covered with a thin DLC film and slowly cooled to $300^{\circ} \mathrm{F}$ at a rate of $0.66^{\circ} \mathrm{F}$ per minute. The temperature was maintained for 6 hours and then increased to 300 ${ }^{\circ} \mathrm{F}$ at a rate of $0.33{ }^{\circ} \mathrm{F}$ per minute, where it was maintained for 4 hours. The specimens were cooled in the furnace to room temperature to improve the wear resistance of the film. Fig. 2 shows the timetemperature curve for cryogenic treatment of the specimens.

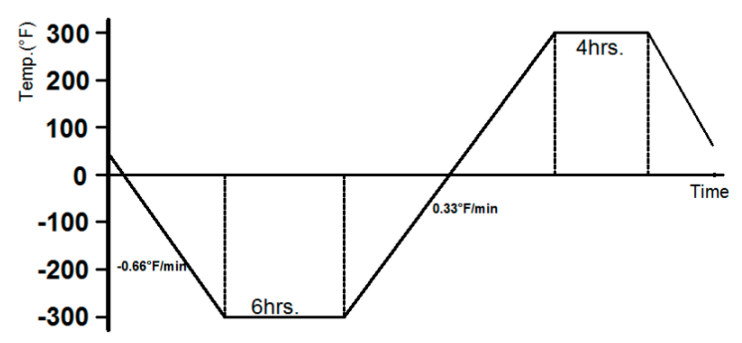

Fig. 2 Time-temperature curve for cryogenic treatment of the specimens

\subsection{Coating structure analysis}

In this study, the coating structure was analyzed using Raman spectroscopy. Generally, when analyzed using Raman spectroscopy, DLC shows two characteristic peaks. Specifically, a G peak at the 1580 $\mathrm{cm}^{-1}$ position, which is primarily because of the symmetrical lattice vibrations caused by carbon atoms in the graphite ring, and a D peak at the $1350 \mathrm{~cm}^{-1}$ position, which is caused by increased structural disorder. The experiment used green light emitted by an argon ion laser at the wavelength of $514.5 \mathrm{~nm}$ to analyze the coating microstructure. The positions of the $G$ and $D$ peaks were analyzed using the Gaussian distribution function to evaluate the structure of the DLC coating and any changes in the film quality.

\subsection{Hardness test}

The study used a nanoindenter hardness machine to assess the hardness of the coating. The tip of a tetrahedron-shaped nano-crystal diamond was used to penetrate the specimen surface from tens to thousands of $\mathrm{nm}$. The depth was used to determine the surface area of the three connected sides of a tetrahedron. Then, the force exerted on the specimen surface was divided by the area to obtain the hardness value of the material. During the experiment, five points of the specimens were measured. Indentations approximately $100 \mathrm{~nm}$ in depth were made at the five points, at a load rate of $6000 \mu \mathrm{m} / \mathrm{sec}$. The average hardness $(\mathrm{GPa})$ and Young's modulus values (GPa) were also obtained.

\subsection{Wear resistance test}

In this experiment, a pin-on-disk wear testing machine was used to measure the friction coefficient and wear-resistance characteristics of the coating. Tungsten carbide balls were used to compare the specimens and level of wear to determine the friction coefficient $(\mu)$ and wear rates. The wear rates were then used to assess the wear-resistance characteristics. During the experiment, the relative humidity was 53\%, and the temperature was $22{ }^{\circ} \mathrm{C}$. The parameters 
employed for the experiment are listed in Table 4. The friction coefficient and formulae of wear rates are expressed as Formulae (1) and (2).

Table 4 Wear-resistance parameters

\begin{tabular}{ll}
\hline Loading & $\mathbf{1 0} \mathbf{N}$ \\
\hline Rotational speed & $200 \mathrm{rpm}$ \\
\hline Pin material & Carbide, diameter $=5.0 \mathrm{~mm}$ \\
\hline Stop condition & Revolution time $60 \mathrm{~min}$ \\
\hline
\end{tabular}

$\mathrm{F}=\mu \mathrm{N}$

$\mathrm{F}=$ friction force $(\mathrm{N}), \mu=$ friction coefficient, $\mathrm{N}=$ normal force (loading) $(\mathrm{N})$

$W R=\frac{\pi \mathrm{DA}}{\mathrm{Pd}}$

$W R=$ wear rates $\left(\mathrm{mm}^{3} / \mathrm{Nm}\right), \mathrm{D}=$ wear diameters $(\mathrm{mm}), \mathrm{A}=$ sectional areas of the friction $\left(\mathrm{mm}^{2}\right), \mathrm{P}=$ normal force (loading) $(\mathrm{N}), \mathrm{d}=$ gliding distances $(\mathrm{m})$

\section{Results and discussion}

The study used PVD to produce hydrogen containing DLC films in the surface of NAK80 mold steel. During film production, silicon was doped and the acetylene to hydrogen gas flow ratio was altered. The prepared specimens then underwent cryogenic treatment to increase the wear resistance of the DLC film and the lifetime of molds in an effort to reduce production costs.

\subsection{Substrate microstructure observation}

To precipitate prehardened steel, NAK80 mold steel possesses ideal and dense mirror-polished properties, with uniform hardness from the steel surface to the center. During the experiment, the surface microstructure of NAK80 mold steel and cryogenically treated NAK80 steel was observed. Before observation, the specimens were polished to a mirror finish, and the material surface was etched using 5\% Nital (95 ml ethanol $+5 \mathrm{ml}$ nitrate). Finally, the surface of the microstructure was observed using an optical microscope. The etched microstructures are shown in Figs. $3 a$ and $3 b$. As indicated by the microscopic images of the microstructures, the substrates with and without cryogenic treatment were carbides distributed in the martensite base. Except for the large primary carbides, smaller and uniformly dispersed second carbides precipitated in the martensite base after the specimen underwent cryogenic treatment. After cryogenic treatment, the specimens exhibited substantially smaller grains. The carbide was more delicate; the grains had increased in number and were uniformly distributed. ${ }^{9-10}$

Fig. 3 Substrate microstructure: $a$ NAK80

substrates without cryogenic treatment; and

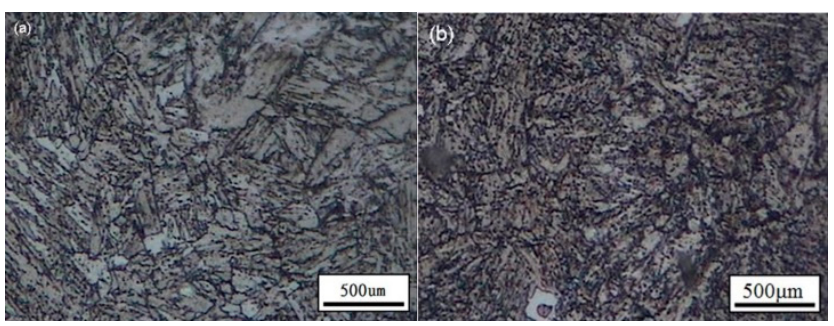

b NAK80 substrates with cryogenic

treatment

3.2 Raman spectroscopy coating analysis

Generally, DLC films analyzed using Raman spectroscopy exhibit two characteristic peaks. One peak for the G-band at the position of $1580 \mathrm{~cm}^{-1}$, and another for the D-band at the position of $1350 \mathrm{~cm}^{-1}$. The wave height ratio of the D- and G-bands can be called the Raman intensity ratio $\left(\mathrm{I}_{\mathrm{D}} / \mathrm{I}_{\mathrm{G}}\right)$. When the $\mathrm{I}_{\mathrm{D}} / \mathrm{I}_{\mathrm{G}}$ of the DLC film increases, the $\mathrm{sp}^{2}$ content increases, and the $\mathrm{sp}^{3}$ content declines, resulting in a relatively low hardness value. This phenomenon is known as graphization. Conversely, when the $\mathrm{I}_{\mathrm{D}} / \mathrm{I}_{\mathrm{G}}$ of the DLC film declines, its $\mathrm{sp}^{2}$ content declines, and the $\mathrm{sp}^{3}$ content increases, which increases the substrate hardness. 
For this experiment, green light emitted by a sub-ion laser at a wavelength of $514.5 \mathrm{~nm}$ was used to conduct measurements. The scanning range was from 900 to $1900 \mathrm{~cm}^{-1}$, and each spectrum underwent Gaussian fitting using the data processing software Origin to decompose the bond energy into $\mathrm{sp}^{2}$ and $\mathrm{sp}^{3}$ bonds. The absorption peak position and Raman intensity ratio $\left(\mathrm{I}_{\mathrm{D}} / \mathrm{I}_{\mathrm{G}}\right)$ of the $\mathrm{G}$ - and D-bands were determined; the values of which are presented in Table 5 and Fig. 4.

Table 5 Raman intensity ratio (ID/IG) analysis

\begin{tabular}{|c|c|c|c|}
\hline Specimen & $\begin{array}{l}\text { D-band } \\
\text { position }\end{array}$ & $\Delta W_{D} \begin{array}{l}\text { G-band } \\
\text { position }\end{array}$ & $\Delta \mathbf{W}_{\mathbf{G}} \mathbf{I}_{\mathbf{D}} / \mathbf{I}_{\mathbf{G}}$ \\
\hline 1 & $1285 \mathrm{~cm}^{-1}$ & $491.31542 \mathrm{~cm}^{-1}$ & 177.50 .588 \\
\hline $\mathrm{C} 1$ & $1364 \mathrm{~cm}^{-1}$ & $305.31546 \mathrm{~cm}^{-1}$ & 153.70 .484 \\
\hline 2 & $1363 \mathrm{~cm}^{-1}$ & $292.11538 \mathrm{~cm}^{-1}$ & 140.60 .647 \\
\hline $\mathrm{C} 2$ & $1370 \mathrm{~cm}^{-1}$ & $286.91531 \mathrm{~cm}^{-1}$ & 138.70 .532 \\
\hline 3 & $1317 \mathrm{~cm}^{-1}$ & $455.41531 \mathrm{~cm}^{-1}$ & 123.31 .483 \\
\hline $\mathrm{C} 3$ & $1387 \mathrm{~cm}^{-1}$ & $299.61577 \mathrm{~cm}^{-1}$ & 1.012 \\
\hline
\end{tabular}

As indicated by the data provided in Table 5, when a minimal amount of silicon was added, the Raman-analyzed G-band shifted slightly toward lower wavenumbers. An increase in the half width and height of the G-band and a decline in the Raman intensity ratio $\left(\mathrm{I}_{\mathrm{D}} / \mathrm{I}_{\mathrm{G}}\right)$ were observed. In addition, the graphite-like pieces in the film shrank and declined in number, whereas the diamond-like bases increased. ${ }^{11}$ The $\mathrm{I}_{\mathrm{D}} / \mathrm{I}_{\mathrm{G}}$ ratio of each specimen measured less than 1.8; thus, the crystallized particles were smaller than $2.5 \mathrm{~nm}$, and the DLC film of the specimens belonged to non-crystallized structures.

The $\mathrm{I}_{\mathrm{D}} / \mathrm{I}_{\mathrm{G}}$ ratios obtained in the experiment are shown in Table 5. The value for Specimen C1 was 0.484 , that for Specimen 1 was 0.585 , that for specimen C2 was 0.532, that for Specimen 2 was 0.647, that for Specimen C3 was 1.012, and that for Specimen 3 was 1.483 . These results indicated that after cryogenic treatment, the DLC film Raman
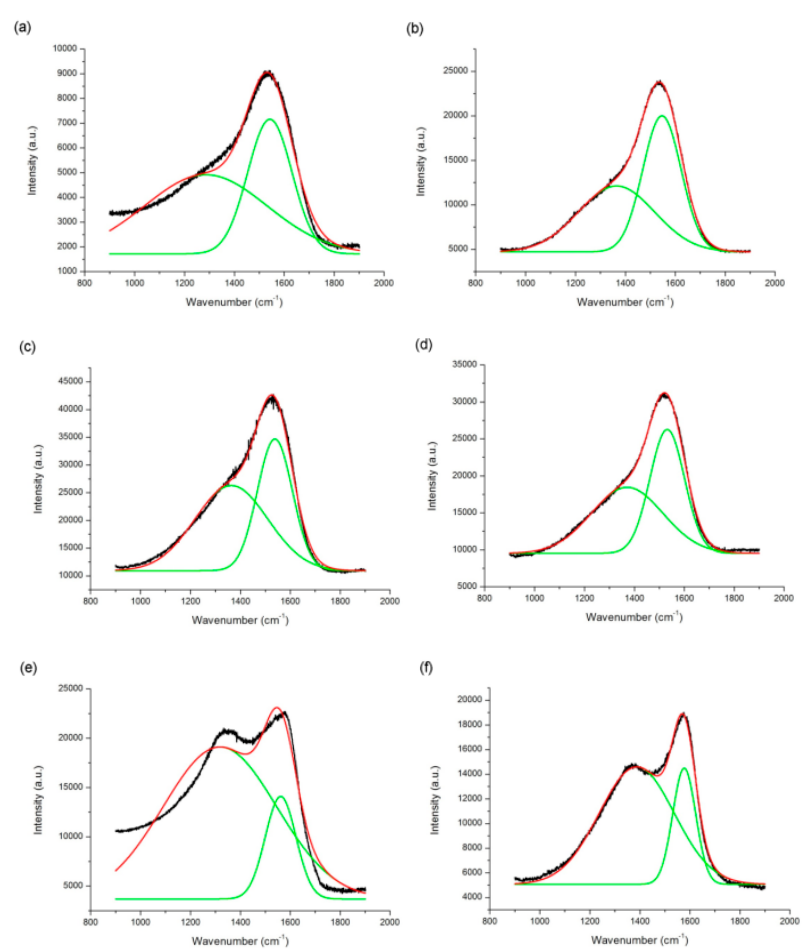

Fig. 4 Raman spectroscopy analysis: $a$

Specimen 1; $b$ Specimen C1; $c$ Specimen 2; $d$ Specimen C2; and $e$ Specimen 3; $f$ Specimen

C3

intensity ratio was smaller compared to that without cryogenic treatment. Therefore, when the DLC film is cryogenically treated, the surface exhibits additional $\mathrm{sp}^{3}$ bonding configurations, and this increase in $\mathrm{sp}^{3}$ bonding configurations increases the hardness of the DLC film.

\subsection{Hardness test analysis}

In this study, a Vickers hardness tester was used to measure the hardness value of NAK80 mold steel with and without cryogenic treatment; the results are presented in Table 6. A nanoindenter was used to measure the hardness of the DLC film, and the total indentation depth was controlled to less than $100 \mathrm{~nm}$ to avoid substrate effect. Five spots were chosen for determining the average values of each specimen; area effect to the samples was avoided. The results obtained matched the Raman intensity ratio, as shown in Table 7. 
Table 6 Hardness values of the NAK80 substrate specimens after cryogenic treatment

\begin{tabular}{lrrrrrr}
\hline \multicolumn{2}{r}{ Specimen1st } & 2nd & 3rd & 4th & 5th & $\begin{array}{l}\text { Average } \\
\text { Value }\end{array}$ \\
\hline $\mathrm{S}$ & 381 & 379 & 378 & 380 & 379 & 379.4 \\
$\mathrm{CS}$ & 382 & 380 & 380 & 381 & 382 & 381 \\
\hline
\end{tabular}

Table 7 Average nanoindentation hardness and

\begin{tabular}{lllll}
\multicolumn{5}{c}{ Young's modulus values } \\
\multicolumn{5}{c}{ Young's } \\
Specimen & H(GPa) & $\begin{array}{l}\text { Yoindenter } \\
\text { modulus }\end{array}$ & H/E & $\mathbf{I}_{\mathbf{D} / \mathbf{I}_{\mathbf{G}}}$ \\
& & $(\boldsymbol{G P a})$ & & \\
\hline 1 & 55.68 & 286.34 & 0.194 & 0.588 \\
$\mathrm{C} 1$ & 59.34 & 300.91 & 0.197 & 0.484 \\
2 & 53.21 & 247.64 & 0.214 & 0.647 \\
$\mathrm{C} 2$ & 56.18 & 260.01 & 0.216 & 0.532 \\
3 & 52.45 & 241.82 & 0.217 & 1.483 \\
$\mathrm{C} 3$ & 54.71 & 241.70 & 0.226 & 1.012 \\
\hline
\end{tabular}

According to the data provided in Table 7, the hardness of NAK80 mold steel without cryogenic treatment was approximately $379.8 \mathrm{HV}$, and the hardness of that with cryogenic treatment was $381 \mathrm{HV}$. The hardness of the specimens after cryogenic treatment was increased by $1-2 H V$. The reason for this result is that after cryogenic treatment, the austenite retained in the material can be completely transformed into martensite, and residual stress can be eliminated to enable the texture to achieve relatively greater stability. Therefore, the higher the residual austenite content, the lower the relative hardness.

According to the theory proposed by Stan Veprek, ${ }^{12}$ the higher the bond energy among atoms within the layers is, the shorter the bond distance between atoms; comparatively greater hardness can also be achieved. Therefore, in this study, a siliconcarbon bond was smaller in the bond energy and longer among atom lengths compared with a carboncarbon bond. The addition of silicon elements therefore exerts a negative effect on film hardness. When DLC film is doped in silicon, the $\mathrm{sp}^{3}$ content of the film's internal structure declines, leading to graphization, which reduces the hardness of the DLC film.

Data in Table 8 show that when the $\mathrm{I}_{\mathrm{D}} / \mathrm{I}_{\mathrm{G}}$ value of the DLC film was increased, the $\mathrm{sp}^{2}$ content increased, the $\mathrm{sp}^{3}$ content decreased, and the relative hardness was reduced. By contrast, when the $\mathrm{I}_{\mathrm{D}} / \mathrm{I}_{\mathrm{G}}$ value of the DLC film was reduced, its $\mathrm{sp}^{2}$ content declined, the $\mathrm{sp}^{3}$ content rose, and the relative hardness increased. The hardness of Specimen C1 was 59.34 GPa and the $\mathrm{I}_{\mathrm{D}} / \mathrm{I}_{\mathrm{G}}$ value was 0.484 . The hardness and strength of the DLC film was most outstanding. The ranking of the hardness of the coating specimens was $\mathrm{C} 1>\mathrm{C} 2>\mathrm{C} 3>1>2>3$.

Table 8 Friction coefficient and ID/IG parameters

\begin{tabular}{lll}
\hline Specimen & $\begin{array}{l}\text { Friction } \\
\text { coefficient }(\boldsymbol{\mu})\end{array}$ & $\mathbf{I}_{\mathbf{D}} / \mathbf{I}_{\mathbf{G}}$ \\
\hline $\mathrm{S}$ & 1.040 & \\
$\mathrm{CS}$ & 0.942 & \\
1 & 0.263 & 0.588 \\
$\mathrm{C} 1$ & 0.221 & 0.484 \\
2 & 0.252 & 0.647 \\
$\mathrm{C} 2$ & 0.207 & 0.532 \\
3 & 0.192 & 1.483 \\
$\mathrm{C} 3$ & 0.136 & 1.012 \\
\hline
\end{tabular}

3.4 Wear test analysis

This experiment involved using the pin-on-disk wear test, employing a tungsten carbide ball to abrade the specimens. This process was used to calculate the friction coefficient $(\mu)$ and wear rate. The wear resistance of each specimen was determined according to the wear rate.

\subsubsection{Friction coefficient analysis}

The experiment results showed that the friction coefficient of the NAK80 mold steel specimens 
ranged between 0.85 and 1.2. After DLC coating, the friction coefficient of Specimens 1, 2, and 3 ranged between 0.18 and 0.3 and the friction coefficient of the NAK80 mold steel after cryogenic treatment ranged between 0.94 and 1.15. After cryogenic treatment, the coefficients for Specimens C1, C2, and C3 ranged between 0.05 and 0.24 , as shown in Fig. 5. These findings indicate that applying cryogenic treatment to the DLC film can reduce the friction coefficient. The average friction coefficient of the specimens matched the values provided using Raman spectroscopy, as shown in Table 8 . Increases in the $\mathrm{I}_{\mathrm{D}} / \mathrm{I}_{\mathrm{G}}$ ratio promoted the graphization of the DLC film; thus, a solid lubricating effect was generated to reduce the friction coefficient.
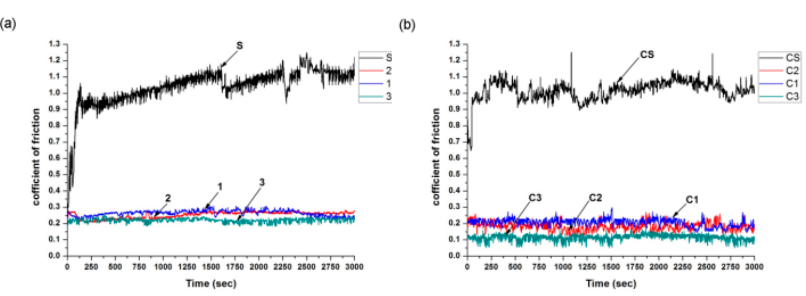

Fig. 5 Friction coefficient analysis: $a$ specimens without cryogenic treatment; and $b$ specimens with cryogenic treatment

\subsubsection{Wear rate analysis}

The experiment results showed that Formulae (1) and (2) can be used to obtain the wear rate of each specimen, as shown in Table 9. The Raman spectroscopy and nanoindentation test results corresponded with the wear rate measurement. The rating of the wear resistance of the specimens was $\mathrm{C} 3>$ $3>\mathrm{C} 2>2>\mathrm{C} 1>1>\mathrm{CS}>\mathrm{S}$. A comparison of the wear rate and the Raman intensity ratio $\left(\mathrm{I}_{\mathrm{D}} / \mathrm{I}_{\mathrm{G}}\right)$ indicated that when the DLC film $I_{D} / I_{G}$ increased, the wear rate declined, and vice versa. The greater the $\mathrm{I}_{\mathrm{D}} / \mathrm{I}_{\mathrm{G}}$ intensity ratio, the higher the $\mathrm{sp}^{2}$ content, and the higher the degree of graphization, the greater the film graphite content and lubrication. The H/E values obtained through nanoindenter tests and the wear test were used for mutual corroboration to judge the wear rate of DLC films. When the $\mathrm{H} / \mathrm{E}$ value was increased, less strain was expected to accumulate, resulting in superior wear resistance. ${ }^{13-15}$

Table 9 Wear rate and ID/IG parameters

\begin{tabular}{llll}
\hline \multicolumn{2}{c}{ Specimen } & \multicolumn{2}{l}{ Wear rate } \\
& $\left(\mathbf{m m}^{3} / \mathbf{N m}\right)$ & $\mathbf{I}_{\mathbf{D}} / \mathbf{I}_{\mathbf{G}}$ & $\mathbf{H} / \mathbf{E}$ \\
\hline $\mathrm{S}$ & $11.2 \times 10^{-6}$ & & \\
$\mathrm{CS}$ & $10.8 \times 10^{-6}$ & & \\
1 & $0.56 \times 10^{-6}$ & 0.588 & 0.194 \\
$\mathrm{C} 1$ & $0.41 \times 10^{-6}$ & 0.484 & 0.197 \\
2 & & $0.36 \times 10^{-6}$ & 0.6470 .214 \\
$\mathrm{C} 2$ & & $0.21 \times 10^{-6}$ & 0.5320 .216 \\
3 & & $0.14 \times 10^{-6}$ & 1.4830 .217 \\
$\mathrm{C} 3$ & & $0.10 \times 10^{-6}$ & 1.0120 .226 \\
\hline
\end{tabular}

Wear is an abrasive and damaging effect that occurs when two solid surfaces are in contact, resulting in the surface layers being rubbed away. The four widely accepted mechanisms of wear are (1) adhesion, (2) abrasion, (3) surface fatigue, (4) and tribochemical. ${ }^{16}$ The experiment results showed that NAK80 mold steel with and without cryogenic treatment exhibited surface fatigue and adhesion, whereas the DLC films mainly exhibited abrasion, as shown in Fig. 6.
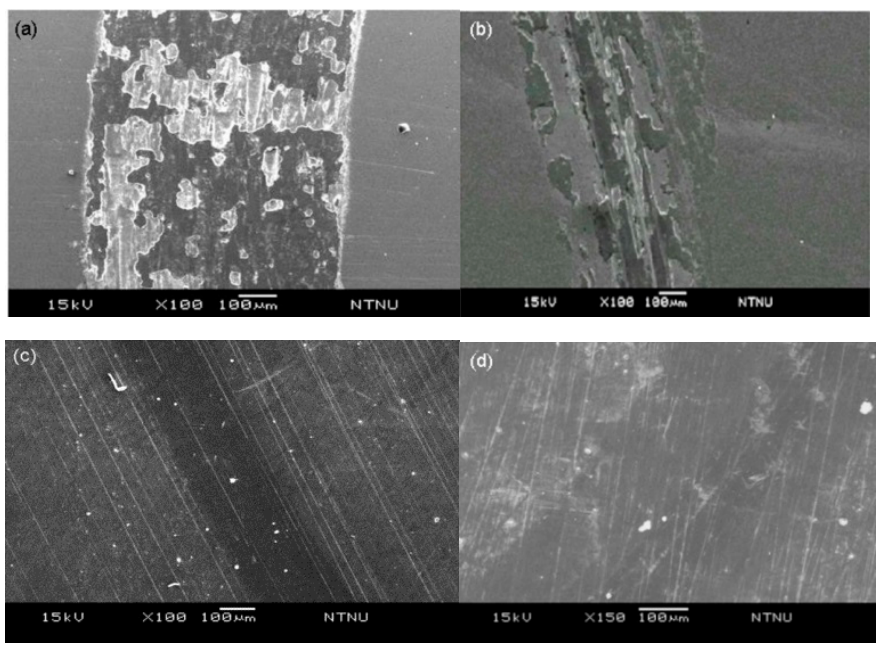

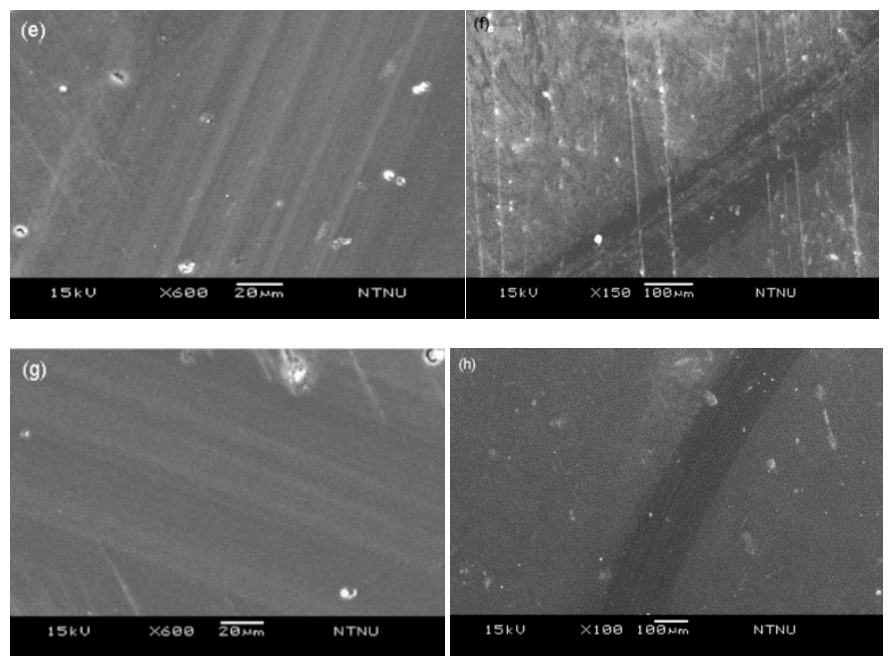

Fig. 6Wear rate of each specimen: $a$ Specimen $S$; $b$ Specimen CS; $c$ Specimen 1; $d$ Specimen C1; $e$ Specimen 2; $f$ Specimen C2; $g$ Specimen 3; and $h$ Specimen C3

\section{Conclusion}

In this study, cryogenic treatment was applied to NAK80 mold steel with DLC films to investigate whether such treatment increases the wear resistance and surface hardness of DLC films. The results of this study were as follows:

1. Observation of the NAK80 mold steel microstructure indicated that the substrates with and without cryogenic treatment were carbides distributed in the martensite base. The specimens that underwent cryogenic treatment showed second carbide precipitation and substantially reduced crystallites in the martensite base.

2. Raman spectroscopy showed that after cryogenic treatment, the surface of the DLC films generated increased $\mathrm{sp}^{3}$ bonding configurations, which increased the DLC film hardness. Increased $\mathrm{I}_{\mathrm{D}} / \mathrm{I}_{\mathrm{G}}$ resulted in DLC graphitization; thus, a solid lubricating effect was generated to reduce the friction coefficient.

3. The wear test revealed that adding silicon to the DLC films increased the graphite content in the film structure. The presence of silicon induced carbon bonding that resembles that of graphite, as confirmed by the increased Raman $\mathrm{I}_{\mathrm{D}} / \mathrm{I}_{\mathrm{G}}$ ratio. An increase in the $\mathrm{I}_{\mathrm{D}} / \mathrm{I}_{\mathrm{G}}$ and $\mathrm{H} / \mathrm{E}$ ratios indicates a decrease in the wear rate of the DLC films; conversely, a decrease in the aforementioned ratios indicates an increase in the wear rate of the films. After the films were cryogenically treated, their wear resistance improved. The wear mechanisms of the cryogenically treated and untreated substrates entailed both adhesion and surface fatigue, whereas the DLC films primarily exhibited abrasion.

\section{References}

1. G. D. Gamulya, Y. L. Ostrovskaya, I. L. Ostapenko, G. N. Presnyakova and V. E. Strel'nitskij: 'Friction behaviour and wear resistance of diamond-like carbon films under cryogenic temperatures', Diam. Relat. Mater., 1994, 3, 1381-1384.

2. S. Thamizhmanii and H. S. MohdNagib: 'Performance of deep cryogenically treated and non-treated PVD inserts in milling', J. Achieve Mater. Manuf. Eng., 2011, 49, 460-466.

3. S. Singh, D. Singh and N. S. Kalsi: 'Experimental analysis of cryogenic treatment on coated tungsten carbide inserts in turning', Int. J. Adv. Eng. Tech., 2012, 3, 290-294.

4. A. Molinari, M. Pellizzari, S. Gialanella, G. Straffelini and K. H. Stiasny 'Effect of deep cryogenic treatment on the mechanical properties of tool steels', J. Mater. Process. Tech., 2001, 118, 350-355.

5. A. C. Ferrari and J. Robertson: 'Interpretation of Raman spectra of disordered and amorphous carbon', Phys. Rev. B, 2000, 61, 95-107.

6. J. Vetter, R. Knaup, H. Dwuletzki, E. Schneidr 
and S. Vogler: 'Hard coatings for lubrication reduction in metal forming', Surf. Coat. Tech., 1996, 86/87, 739-747.

7. R. L. Boxman and S. Goldsmith:

'Macroparticle contamination in cathodic arc coatings: generation, transport and control', Surf. Coat. Tech., 1992, 52, 39-52.

8. C. H. Lai, K. H. Cheng, S. J. Lin and J. W. Yeh: 'Mechanical and tribological properties of multi-element(AlCrTaTiZr)N coatings', Surf. Coat. Tech., 2008, 202, 3732-3738.

9. A. Akhbarizadeh, M. A. Golozar, A. Shafeie and M. Kholghy: 'Effects of austenizing time on wear behavior of D6 tool steel after deep cryogenic treatment', J. Iron Steel Res., 2009, 16, 29-32.

10. Y. P. Chang, H. M. Chou, J. H. Horng, L. M. Chu and Z. W. Huang: 'Effects of deep cryogenic treatment on tribological properties of the tool steel DC53', Mech. Mater., 2013, 311, 477-481.
11. M. Bana and T. Hasegawa: 'Internal stress reduction by incorporation of silicon in diamond-like carbon films', Surf. Coat. Tech. 2003, 16, 1-5.

12. S. Veprek: 'The search for novel, superhard materials', Sci. Tech., 1999, 17, 2401-2420.

13. P. W. Shum, Z. F. Zhou and K. Y. Li: 'Enhancement of adhesion strength and tribological performance of pure carbon coatings on Ti-6Al-4V biomaterials with ion implantation pre-treatments', Tribology, 2007, 40, 313-318.

14. E. Rabinowicz: 'Friction and wear of materials', 2nd ed.; 1995, New York, Wiley.

15. G. Bolelli, L. Lusvarghi, F. PighettiMantini, F. Pitacco and H. Volz: 'Enhanced tribological properties of PECVD DLC coated thermally sprayed coatings', Surf. Coat. Tech., 2008, 202, 4382-4386.

16. T. H. Chuang: 'Failure analysis', 282-336; 2010, Taipei, Taiwan, Wu-Nan.

(C) 2016 by the authors; licensee Preprints, Basel, Switzerland. This article is an open access article distributed under the terms and conditions of the Creative Commons by Attribution (CC-BY) license (http://creativecommons.org/licenses/by/4.0/). 